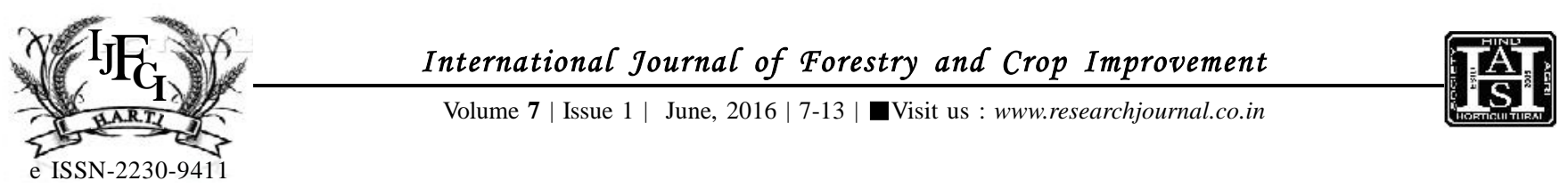

RESEARCH ARTICLE

\title{
Performance evaluation of different tree species for carbon sequestration under wasteland condition
}

\author{
C.N. Hari Prasath, A. Balasubramanian, M. Prasanthrajan and S. RadhaKrishnan
}

\begin{abstract}
A study was conducted to identify suitable fast growing trees under wasteland condition for carbon sequestration. Accordingly, five fast growing trees namely Tectona grandis Linn., Gmelina arborea Roxb., Dalbergia sissoo Roxb., Bambusa vulgaris var. vulgaris and Swietenia macrophylla king were selected for field study under wasteland condition. The performance of these trees was assessed with biometrical traits (height, basal diameter) and eco-physiological traits (transpiration, photosynthesis, intercellular $\mathrm{CO}_{2}$ concentration and stomatal conductance). Among the five species, Dalbergia sissoo exhibited highest growth, productivity and also superior in ecophysiological traits suits for carbon sequestration. The tree species, Bambusa vulgaris var. vulgaris performed well next to Dalbergia sissoo interms of biometric, productivity and eco-physiological parameters. The lowest biometric and productivity was observed in Gmelina arborea. The tree species, Dalbergia sissoo and Bambusa vulgaris var. vulgaris are highly suitable for afforestation in wastelands to attain carbon sequestration benefits.
\end{abstract}

KEY WORDS : Tree species, Wasteland, Carbon Sequestration, Eco-physiological traits

How TO CITE THIS ARTICLE : Hari Prasath, C.N., Balasubramanian, A. Prasanthrajan, M. and Radhakrishanan, S.(2016). Performance evaluation of different tree species for carbon sequestration under wasteland condition. Internat. J. Forestry \& Crop Improv., 7 (1) : 7-13, DOI: 10.15740/HAS/IJFCI/7.1/7-13.

Article Chronical : Received : 27.12.2015; Revised : 02.04.2016; Accepted : 03.05.2016 INDIA

Address of the Coopted Authors : A. Balasubramanian, M. PRASANTHRAJAN AND S. RADHAKRISHNAN, Department of Siliviculture, Forest College and Research Institute (T.N.A.U.), METTUPALAYAM (T.N.) INDIA 